\title{
Essentials in spontaneous ventilation video-assisted thoracoscopic surgery: how we do it
}

\author{
Teodor Horvath $^{1 * \wedge}$, Kamil Hudacek ${ }^{2}$ \\ ${ }^{1}$ Department of Surgery, Faculty Hospital and Faculty of Medicine, Masaryk University Brno, Brno, Czech Republic; ${ }^{2}$ Department of \\ Anaesthesiology, Resuscitation and Intensive Care Faculty Hospital, Masaryk University Brno, Brno, Czech Republic \\ Correspondence to: Teodor Horvath, MD, PhD. Associate Professor of Surgery, Department of Surgery, Faculty Hospital and Faculty of Medicine, \\ Masaryk University Brno, Jihlavska 20, 62500 Brno, Czech Republic. Email: 46543@mail.muni.cz.
}

\begin{abstract}
Spontaneous ventilation non-intubated thoracic surgery (NITS) has roots in authentic tradition, and yet is radically new. It appreciates inherent physiological functions and engages up-to-date knowledge of physiology, pharmacology, and device technology. The interdisciplinary collaboration between surgery and anaesthesia is refined. The compliance of the lungs and the thoracic wall is supported by high-flow nasal oxygenation (HFNO). The depth of anaesthesia with propofol is monitored by bispectral index (BIS). BIS score is optimally maintained between 40-60. The procedures include foreign body extraction, pulmonary wedge resections, thoracic wall or mediastinal tumours extirpation, anatomical pulmonary resection, lobar or sublobar, up to pneumonectomy. The method significantly reduces preoperative preparation and postoperative care. During the preparatory stage of the operation, artificial pneumothorax (PNO) is introduced under propofol sedation and HFNO is performing the utility incision(s) in local anaesthesia. Bupivacaine and lidocaine are used. Then inner intercostal regional anaesthesia in the third to the eighth intercostal space is administered. A vagal block follows using a sheathed long needle. Thereafter, routine thoracic surgery continues without any technical difference in comparison with established video-assisted thoracoscopic surgery (VATS) with intubation and artificial breathing. NITS has one specific feature: the three types of unwitting pulmonary, mediastinal and thoracic wall movement than can emerge after PNO introduction: $1 / \mathrm{mild}, 2 /$ moderate, $3 /$ severe (significant). It is not possible to predict which of these will appear. In mild and moderate types (about $90 \%$ of patients) every kind of procedure is feasible. The severe type signals the need for conversion to an intubation procedure with artificial breathing. Contraindications of NITS include obesity, gastroesophageal reflux disease, large pleural adhesions, and significant pulmonary movement.
\end{abstract}

Keywords: Analgosedation; intercostal anaesthesia; local anaesthesia; pulmonary resection; vagal block

Received: 24 May 2021; Accepted: 20 August 2021; Published: 30 June 2022.

doi: 10.21037/asj-21-37

View this article at: https://dx.doi.org/10.21037/asj-21-37

\footnotetext{
* On behalf The Masaryk University Thoracic Group I: Horváth $\mathrm{T}^{1}$, Hudáček $\mathrm{K}^{2}$, Brat K $\mathrm{K}^{3}$, Dia $\mathrm{M}^{5}$, Ivanecká $\mathrm{D}^{1}$, Ivičič $\mathrm{J}^{1}$, Kališ $\mathrm{V}^{2}$, Kodýtková $\mathrm{A}^{1}$, Koláček $\mathrm{T}^{2}$, Kratochvílová $\mathrm{J}^{2}$, Křenek A ${ }^{1}$, Lakomý $\mathrm{R}^{4}$, Majerčák L ${ }^{7}$, Merta $Z^{3}$, Mitáš L ${ }^{1}$, Moravčík $\mathrm{P}^{1}$, Peňázová $\mathrm{P}^{1}$, Petr Dostalova $\mathrm{P}^{6}$, Plutinsky $M^{3}$, Poprach $\mathrm{A}^{4}$, Prášek $\mathrm{M}^{4}$, Rindoš $\mathrm{R}^{1}$, Španková $\mathrm{M}^{1}$, Špelda $\mathrm{S}^{4}$, Vysloužil $\mathrm{P}^{1}$, Vomela $\mathrm{J}^{1}\left[{ }^{1}\right.$ Department of Surgery; ${ }^{2}$ Department of Anaesthesiology, Resuscitation and Intensive Care Medicine; ${ }^{3}$ Department of Lung Disease and Tuberculosis; ${ }^{1,2,3}$ Faculty Hospital and Faculty of Medicine Masaryk University Brno; ${ }^{4}$ Masaryk Memorial Cancer Institute; ${ }^{5}$ Specialised Health Resort (Odborny lecebny ustav) Jevicko; ${ }^{6}$ Pulmonary Out Patient Centre Hospital Nove Mesto na Morave; ${ }^{7}$ Department of Surgery, Hospital Ivančice].
}

$\wedge$ ORCID: 0000-0002-2956-3689. 


\section{Introduction}

Non-intubated thoracoscopy was born in 1910 (1) and, in the minimally invasive paradigm of the late eighties and early nineties (2), together with video-assisted pulmonary anatomical resections in intubated patients (3) began to blossom (4). A bit later, reports emerged of minor video-assisted thoracic surgical procedures in nonintubated patients (5). Quite suddenly, a new variation of anatomical pulmonary resection is emerging: nonintubated (6). František Burian, inventor of the concept of the physiological operation (7), would certainly rejoice in finding his ideas reborn in the Eastern meadows and successfully breaking new ground: the thorax. An interesting shift in lung surgery is currently underway-spontaneous ventilation video-assisted thoracoscopic surgery (VATS) (8).

\section{Fabulous simplicity}

Using analgosedation with propofol and high-flow nasal cannula (HFNC) oxygenation, the thoracic port(s) is(are) inserted under local anaesthesia by lidocaine and bupivacaine. Then, intrathoracic local anaesthesia is administered from the third up to the eighth intercostal nerves. Unwanted lung movement is naturally overcome by pneumothorax. The cough reflex is muted by a local injection of local anaesthetics subpleurally near the vagus nerve in the pulmonary hilum after carefully moving the pulmonary parenchyma aside, if this hasn't already formed as a result of a thoroughly considered and successfully completed positioning of the patient's body on the operating table, working hand in hand with the willingly cooperation of gravity and the keen assistance of the anaesthetist is needed.

Further principles include: small, rationally thoughtout incisions, tending towards a refined care, accuracy, precision, efficiency, effectivity, hypothermia prevention, sufficient coagulation and suction, with all edges rounded. Clear communication with a genuinely collaborative and sensitive anaesthetist during the procedure is essential, and then a lobectomy with complete lymphadenectomy is done. Rinse. Apply a pressure probe through the anaesthetic mask at 30 torrs. Then carefully close the camera port and the utility incision. A solitary thoracic tube is then inserted diagonally through the intercostal space. Its inner diameter is not narrowed by the upper nor lower rib due to gradually turning direction of the tube. This is connected to a closedwater sealed drainage as given by Gotthard Bülau (9), its originator. After a period of some hours spent in the recovery room, the patient is then, as a rule, transferred to a standard ward. By seeing the clinical status and hearing the auscultation findings, the fact that the residual pulmonary parenchyma is inflated becomes evident. A chest X-ray is then checked on the first postoperative day. In cases where all goes smoothly, the thoracic tube is extracted on the second or third postoperative day. Then the residual pulmonary parenchyma inflation is checked by $\mathrm{X}$-ray and it is usual to release the patient on the third or fourth postoperative day.

\section{General aspects and particular form}

Let's consider the main aspects of spontaneous ventilation video-assisted thoracoscopic surgery interpret them clearly, and, in the light of sustainable development, outline the areas of the discipline they touch upon in their creative simplicity: professionalism in a precise and personal form, procedural and economic effectiveness, and the biological response to the operative impact.

It's important not to jump to any conclusions prematurely. To watch, particularly as the emphasis on the use of physiological knowledge in surgical practice is not, in general, new. This intellectual spark originated in Middle-European Czech grasslands. Later, it appeared again in the Formosan meadows bringing pure and unbridled invention in this new topic with a surprisingly natural and beneficial impact: routine anatomical pulmonary resection in the spontaneously breathing patient, namely:

* No placing of the double-lumen endotracheal tube;

* No artificial respiration;

* No administration of the drugs necessary for artificial respiration;

* No postoperative intensive care;

* Increased perioperative patient comfort;

* Potency for decreased inflammatory response in the organism.

Highlight the professional skill and elegance of both the surgery and the anaesthesiology in their inseparably interwoven connectivity.

The seven subjects mentioned above may create seventy-seven objections; sprout immediate contrasts with a multitude of dramatic layers. Such is life. Real diversity guaranties perfection. That's what really matters.

This brings to mind the pathomechanisms of intubated (versus non-intubated) VATS, which were reviewed by Tommaso Claudio Mineo and Federico Tacconi of Rom (10), 
cite in particular:

(I) Ventilator associate lung injury (VALI) results in a compartmental inflammatory status which, in turn, leads to interstitial edema, loss of surfactant, a ventilation-to-perfusion mismatch, and decreased compliance. In patients with pre-existing lung disease, VALI can evolve into an apparent acute lung injury. Subclinical VALI possibly leading to minor respiratory impairment can still occur in healthy lungs, depending on the extent of surgical trauma.

(II) One-lung ventilation (OLV) related injury in the dependent lung induces a ventilation-to-perfusion mismatch, which promotes further inflammatory changes. The hypoxic environment occurring in the non-dependent (non-ventilated) lung causes tissue acidosis, alveolar edema, vascular congestion, cytokine release, and an increased malondialdehyde level. These changes can occur early on, even after minor operations and even in the absence of surgical trauma. During re-ventilation, higher oxygen fractions trigger an oxidative burst, leading to an accumulation of neutrophil and macrophage activation.

(III) Extrapulmonary side effects of general anaesthesia (GA) and OLV are mediated by the flushing of cytokines toward the systemic circulation, and may include liver injury, weakened natural-killer cells and arrhythmias. The latter also include transient QT-tract prolongation, which has been shown to occur in up to $80 \%$ of patients with the possible development of torsade de pointes.

(IV) Hypoxemia-defined as $\mathrm{SaO}_{2}<90 \%$, with an inhaled oxygen fraction of 0.5 occurs in $10 \%$ of thoracic operations, mostly during right procedures, in the supine position, and in heavy smokers. Double-lumen tube dislodgement is also a frequent cause.

(V) Tracheobronchial rupture. Although its estimated rate is quite low $(1 / 20,000)$, tracheobronchial rupture may carry a mortality rate as high as $22 \%$. Women seem to be at higher risk, probably as a result of the smaller calibre of their airways. Deteriorated clinical conditions and radiotherapy also significantly increase the risk; in rare cases, injury to the hypopharynx, esophagus, and vocal cords may also occur, however, reliable numbers are not available here.
All these represent a wide field for the future programmes of non-intubated thoracic surgery (NITS) research.

\section{The procedure}

All procedures performed in this study were in accordance with the ethical standards of the institutional and/or national research committee(s) and with the Helsinki Declaration (as revised in 2013). Written informed consent was obtained from the patient for publication.

The intrinsic development of the spontaneous ventilation VATS has been accurately described (10). The anaesthesiological proportion has been clearly evaluated $(11,12)$ and the oncological aspect of the method is finally emerging (13). Many particular approaches through the appropriate thoracic region into the relevant intrathoracic field are widely documented in current literature (14). They have countless individual variants, each one with its own advantages and disadvantages. Let us deal here with general principles only.

(I) Pay close attention to positioning. Support the body at the waist using a pad to avoid straining the vertebral column. The thorax is found along the line connecting the lower end of the scapula to the nipple and is supported underneath by a roller of soft foam with a $15-\mathrm{cm}$ diameter placed parallelly to this line. Opening the intercostal spaces is further assisted by the angle of the operating table in the thoracolumbar area, lowering of the thorax position by 30 degrees. The upper arm is not elevated, it is stretched forward horizontally. The lower arm is also in the horizontal position but a little lower. The operating surgeon usually stands, from the view of anaesthetist, on the right side, with the theatre nurse at their right hand. Work from below, so that the axis of any instrument in use is parallel to the camera view. Using two or three ports the camera port should be placed distally enough along the middle auxiliary line. Optimal image stability is supported by the focused attention of an assisting surgeon and the use of a cuffed port.

(II) Administer infiltrative local anaesthesia in an ordinary $75 \mathrm{~kg}$ patient in the case of uniportal procedure over the whole area of the incision and the entire depth of the thoracic wall, 10 millilitres $(\mathrm{mL})$ of lidocaine $2 \%$ together with $10 \mathrm{~mL}$ bupivacaine $0.5 \%$ in the course of the intercostal space. This is usually sufficient. These 200 milligrams ( $\mathrm{mg}$ ) of 
lidocaine represent approximately two thirds of the maximum daily dose (MDD) $4.5 \mathrm{mg} / 1 \mathrm{~kg}$ of body weight (bw), i.e., in a $75-\mathrm{kg}$ patient $337 \mathrm{mg}$. The operating team has further more as $100 \mathrm{mg}$ (i.e., $5 \mathrm{~mL}$ ) in reserve. The MDD of bupivacaine marketed under the branch name marcaine is $5.5 \mathrm{mg} / 1 \mathrm{~kg}$ bw. This represents $80 \mathrm{~mL}$ of the drug for a patient of $75 \mathrm{~kg}$ bw. For each intercostal nerve blockade from the third to the eighth intercostal space use $2 \mathrm{~mL}$ $0.5 \%$ marcaine administered subpleurally about $2 \mathrm{~cm}$ laterally from the thoracic sympathetic bundle. Altogether $12 \mathrm{~mL}$ of the drug. A further 4 to $6 \mathrm{~mL}$ of marcaine $0.5 \%$ are satisfactory for the vagal block using the only unusual VATS instrument: the long "Hilar Needle" protected by a metal sheet. This is marketed under Instrument Product No.: 7657-1L, 7657-2L of WISAP Medical Technology GmbH (www.wisap.de). The surgeon removes the needle immediately before the sub-pleural application of the drug.

The whole of the above-mentioned amount of approximately $28 \mathrm{~mL}$ of marcaine $0.5 \%$ (i.e., $150 \mathrm{mg}$ ) reaches even less as one third of MDD, i.e., in a $75-\mathrm{kg}$ bw patient it would be $412 \mathrm{mg}$. A biportal or tri-portal procedure usually requires $4 \mathrm{~mL}$ of lidocaine $2 \%$ and $16 \mathrm{~mL}$ of marcaine $0.5 \%$ for utility incision(s) and $2 \mathrm{~mL}$ of lidocaine $2 \%$ with $8 \mathrm{~mL}$ of marcaine $0.5 \%$ for the camera port. The routine need for a three-port operation under these circumstances represents, in total, $10 \mathrm{~mL}$ of lidocaine $2 \%$ and $50 \mathrm{~mL}$ of marcaine $0.5 \%$-both of which are satisfactorily within permissible doses.

(III) At the start of the operation, after surgically disinfecting the skin, use a sufficient amount of surgical towelling-which also assists in keeping the patient warm. This has the advantage, for example, of allowing the magnetic pad to be safely fixed to the towels with a single pean. After placing surgical towels on a sufficiently long and wide operating field, the contours of the scapula are clearly delineated, and the arch around the areola, around the spina iliaca, and the whole middle axillary line are painted with skin marker.

(IV) Create the working incision with a careful eye. Open the wound with a pean held in one (usually the left) hand. Penetrate depth using the electrocautery held in the other (usually the right) hand or pull the muscle fibers apart without intersecting them. We prefer the second option.

For the bi-portal procedure, locate the utility incision in the anterior axillary line. For the triportal procedure, the posterior utility incision is situated under the lower angle of the scapula. The advantage of two utility incisions is that four hands can work intrathoracically. The camera is operated by a second assistant, also facing one of the surgeons. The second assistant watches the second monitor located behind the surgeon and/ or on a third monitor placed on the long axis of the operating table by the legs of the patient.

The location of the anterior utility (incision) of $3-4 \mathrm{~cm}$ length is on the anterior axillary line level with the anterior end of the third rib or on the level of the boundary of the middle and lower third of the scapula respectively. It goes in at an oblique angle-with respect to the intercostal space. Create the posterior utility (incision) under the lower angle of the scapula on the posterior axillary line.

Detailed attention needs to be given to both their creation and closure.

(V) During the opening of the pleural space or the initial manipulation of the pleura or the lung, and at the insertion of the Alexis protector/retractor into the wound, the patient might cough. The anaesthetist, in the role of a sovereign partner, monitors the ongoing state of affairs. In such a case where the cough is repeated, the anaesthetist responds with an i.v. administration of a small amount of anodyne $(1 \mathrm{mg}$ of morphine or $25 \mu \mathrm{g}$ of fentanyl) supported, if necessary, by the i.v. administration of a small amount of lidocaine ( $1 \mathrm{~mL}$ of $2 \%$ solution) whilst monitoring the ventilatory and circulatory parameters accordingly. The surgeon immediately follows this with the administration of an intercostal block-in each of $3^{\text {rd }}$ to $7^{\text {th }}\left(8^{\text {th }}\right)$ intercostal space paravertebrally, about $2 \mathrm{~cm}$ away from thoracic sympathetic bundle (Figure 1).

The requirement of intravenous general anaesthetics will be reduced after complete onset of intercostal nerve blocks (usually several minutes later). Careful adjustment of anaesthetic depth goaled with similar bispectral index (BIS) levels is essential cause too deep anaesthesia may follow with an effort respiration.

(VI) The intercostal block is a simple issue. Holding an 


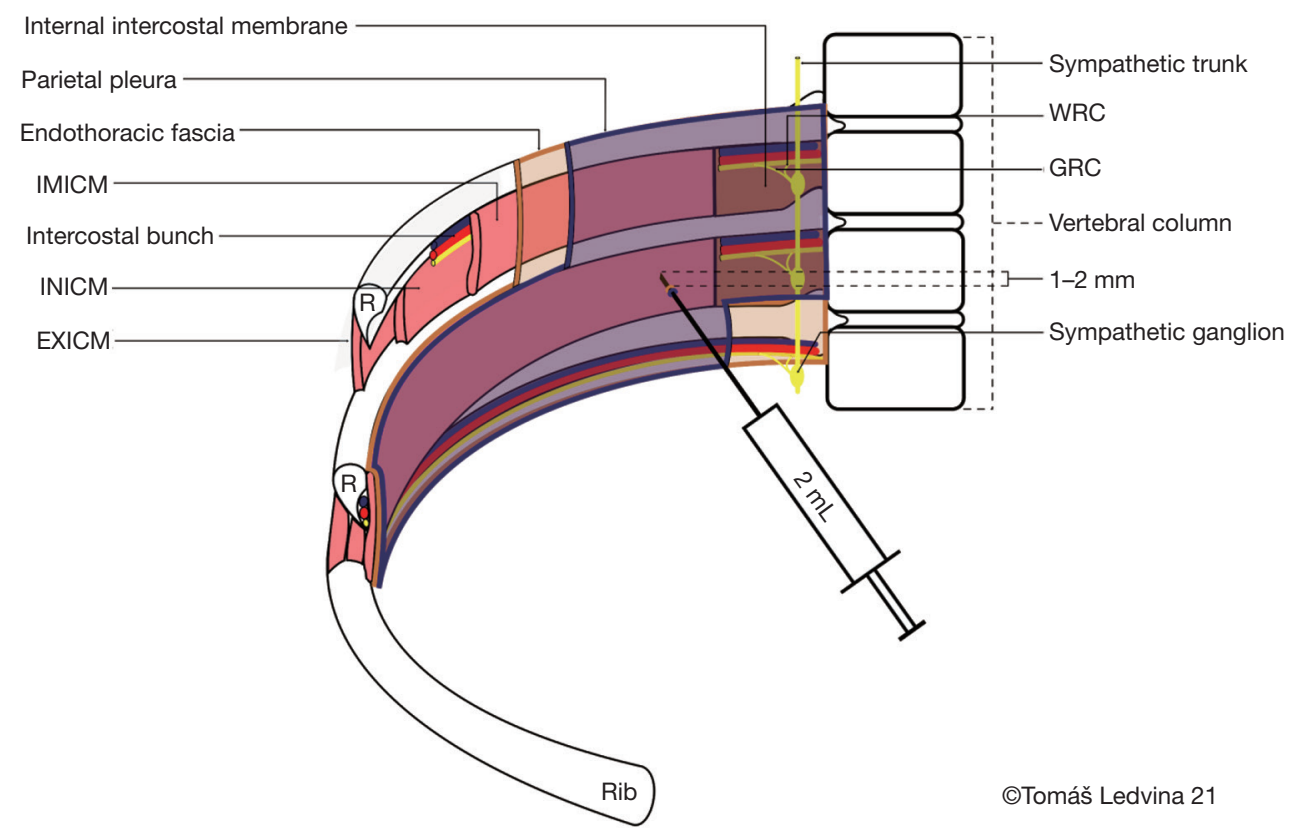

Figure 1 Internal intercostal nerve block-about $2 \mathrm{~cm}$ laterally from the sympathetic bundle. R, rib; IMICM, innermost intercostal muscles; INICM, internal intercostal muscles; EXICM, external intercostal muscles; WRC, white ramus communicans; GRC, grey ramus communicans. Permission is obtained from the creator.

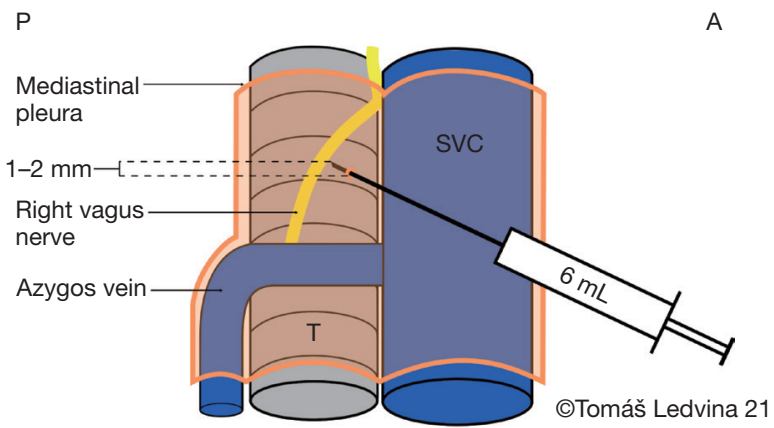

Figure 2 Right side vagal block-above the azygos vein. T, trachea; SVC, superior vena cava; A, anterior; P, posterior. Permission is obtained from the creator.

orange or green butterfly needle by the wing, with a mild curved thoracoscopic instrument, a nodal or pulmonary grasper (e.g., endoFoerster with shaft) in the right hand (hold the instrument with the convexity downward) take a $20-\mathrm{mL}$ syringe with $0.5 \%$ marcaine in the left hand. Introduce the needle about 1 to $2 \mathrm{~mm}$ under the pleural surface and then administer the drug. Use about 1.5 to $2 \mathrm{~mL}$ to a single intercostal nerve. After the intercostal nerve blocks, wait for several minutes

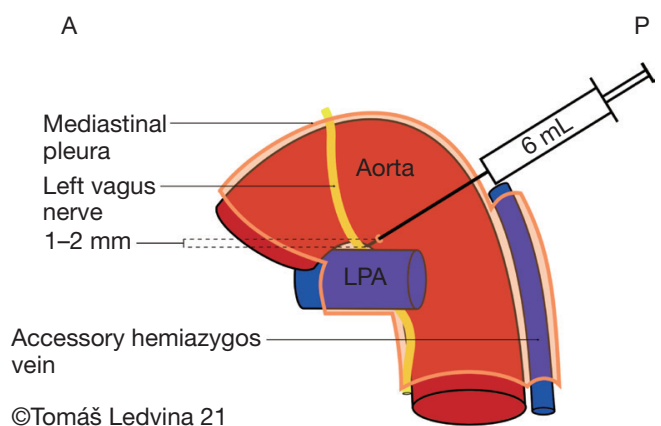

Figure 3 Left side vagal block-beneath the aortic arch. A, anterior; P, posterior; LPA, left pulmonary artery. Permission is obtained from the creator.

and observe the smoothness of the ventilation before performing the vagal nerve block.

Before the vagal block, slowly compress the pulmonary parenchyma moving it gracefully away from the hilus with some gentle pressure using an endoFoerster or endoDuval placed on the lung which has already been partially collapsed by pneumothorax. This is done only to a measure that facilitates the administration of local anaesthetic to block the vagus nerve cough reflex, respectively, 
a subpleural infiltration with $4-6 \mathrm{~mL}$ of $0.5 \%$ marcaine-on the right side above the azygos vein further back (Figure 2), and on the left side between the aorta and the bronchus (Figure 3).

(VII) There are three categories of the movement of the lung, mediastinum and thoracic wall: mild, moderate, and significant or severe. The first two categories allow for NITS lung anatomical resection, the third, which is fortunately quite rare, is contraindicative. Before we start surgery, we never know which of them we will experience.

As the surgeon starts the intrathoracic preparation of the procedure, the anaesthesiologist carefully watches the monitor and estimates the moment in which the instrument will touch sensitive pleura. Here, estimating the time masterfully, the aforementioned intravenous microdose of opiate is applied which, according to some, is nothing more than a placebo in this dosage, according to others, it's more than that. Beauty is in the eye of the beholder.

We are getting ready for that. But now let's get back to this specific surgical procedure: a metal instrument, with almost unimaginable delicacy touches the partly collapsed lung. The lung reacts with a greater or less cough. A microdose of morphine immediately follows, which is promptly washed down with physiological solution into the patient's venous line. All of this in correspondence with appropriate values of BIS [40-60], which is somewhat self-evident. Then, proportionately gentle pressure on the lung does not cause the cough reflex and the vagus nerve soon appears slightly to the side of the upper vena cava or on its entrance to the hilum on the left accessible to the administration of the local anaesthetics. This follows immediately.

(VIII) With the modification of two working incisions, work from below and in parallel, with a classic ("thick") videothoracoscopic camera view or with an ultrathin needlescopic camera used in the single port procedure, which uses a working incision located in the middle axillary line intersected with the connecting line of the lower end of the scapula and the nipple. In the uniportal procedure, the effects of the lubrication of the instruments with jelly particularly stand out.

(IX) Technically speaking., the pulmonary parenchyma is pushed from the hilus with some gentle pressure and, at the same time, subtly moved using the instrument softly placed on the partially collapsed lung parallel with its long axis. After the administration of local anaesthetics into the neighbouring areas of the vagus nerve, the undesirable and unexpected movement of the lung during a cough is averted for a few hours.

(X) After these preliminary phases a routine operation begins. Then nothing is in the way of the usual preparation with no difference in the intubated VATS procedure given in your own school.

(XI) As a rule, before leaving the operation-field, carry out the usual checks on the tightness of the bronchial suture using water with an intrabronchial pressure of $30 \mathrm{~cm}$ of water column on the mask with some visual confirmation of the re-expansion of the residual lung parenchyma. The utility incisions are closed using resorbable material usually with a No. 26 needle.

(XII) After ordinary NITS procedures, the patients are monitored for 2-3 hours in the recovery unit (RU) before they return to a standard ward. Thoracic drain(s) is(are) water-sealed. Only extraordinary cases are directed to the intensive care unit.

\section{Conclusions}

In our day, projects need to be comprehensive and remain feasible and flexible with minor changes where necessary. Video-assisted thoracic surgery is no exception. Each detail needs to be seen from a global perspective and planned for well in advance. The spontaneous ventilation non-intubated method is a creative simplification of the discipline harmonised with the concept of sustainable development.

\section{Acknowledgments}

Keen introduction into the method by Jin-Shing Chen, YaJung Cheng, and Ming-Hui Hung was decisive for us. Funding: None.

\section{Footnote}

Provenance and Peer Review: This article was commissioned by the Guest Editor (József Furák) for the series "Spontaneous Ventilation Thoracic Surgery" published in AME Surgical fournal. The article has undergone external peer review. 
Peer Review File: Available at https://asj.amegroups.com/ article/view/10.21037/asj-21-37/prf

Conflicts of Interest: Both authors have completed the ICMJE uniform disclosure form (available at https://asj. amegroups.com/article/view/10.21037/asj-21-37/coif). The series "Spontaneous Ventilation Thoracic Surgery" was commissioned by the editorial office without any funding or sponsorship. TH reports Chairman of High Specialized Centre for Surgical Oncology of the Lung Brno. The authors have no other conflicts of interest to declare.

Ethical Statement: The authors are accountable for all aspects of the work in ensuring that questions related to the accuracy or integrity of any part of the work are appropriately investigated and resolved. All procedures performed in this study were in accordance with the ethical standards of the institutional and/or national research committee(s) and with the Helsinki Declaration (as revised in 2013). Written informed consent was obtained from the patient for publication.

Open Access Statement: This is an Open Access article distributed in accordance with the Creative Commons Attribution-NonCommercial-NoDerivs 4.0 International License (CC BY-NC-ND 4.0), which permits the noncommercial replication and distribution of the article with the strict proviso that no changes or edits are made and the original work is properly cited (including links to both the formal publication through the relevant DOI and the license). See: https://creativecommons.org/licenses/by-nc-nd/4.0/.

\section{References}

1. Jacobaeus HC. Ueber die Möglichkeit die Zystokopie bei Untersuchung seröser Höhlungen anzuwenden. Münch MedWochenschr 1910;57:2090-2.

doi: $10.21037 /$ asj-21-37

Cite this article as: Horvath T, Hudacek K. Essentials in spontaneous ventilation video-assisted thoracoscopic surgery: how we do it. AME Surg J 2022;2:20.
2. Rusch VW, Mountain C. Thoracoscopy under regional anesthesia for the diagnosis and management of pleural disease. Am J Surg 1987;154:274-8.

3. Roviaro G, Varoli F, Rebuffat C, et al. Major pulmonary resections: pneumonectomies and lobectomies. Ann Thorac Surg 1993;56:779-83.

4. McKenna RJ Jr, Houck W, Fuller CB. Video-assisted thoracic surgery lobectomy: experience with 1,100 cases. Ann Thorac Surg 2006;81:421-5; discussion 425-6.

5. Mineo TC. Epidural anesthesia in awake thoracic surgery. Eur J Cardiothorac Surg 2007;32:13-9.

6. Chen JS, Cheng YJ, Hung MH, et al. Nonintubated thoracoscopic lobectomy for lung cancer. Ann Surg 2011;254:1038-43.

7. Burian F. The past and present of plastic surgery: its problems in future society. Br J Plast Surg 1964;17:351-65.

8. Wen Y, Liang H, Qiu G, et al. Non-intubated spontaneous ventilation in video-assisted thoracoscopic surgery: a metaanalysis. Eur J Cardiothorac Surg 2020;57:428-37.

9. Bülau G. Fur die Heber-Drainage bei Behandlung des Empyems. Z Klin Med 1891;18:3145.

10. Mineo TC, Tacconi F. From "awake" to "monitored anesthesia care" thoracic surgery: A 15 year evolution. Thorac Cancer 2014;5:1-13.

11. Yang JT, Hung MH, Chen JS, et al. Anesthetic consideration for nonintubated VATS. J Thorac Dis 2014;6:10-3.

12. Ruszkai Z, Szabó Z. Maintaining spontaneous ventilation during surgery - a review article. J Emerg Crit Care Med 2020;4:5.

13. Furák J, Paróczai D, Burián K, et al. Oncological advantage of nonintubated thoracic surgery: Better compliance of adjuvant treatment after lung lobectomy. Thorac Cancer 2020;11:3309-16.

14. Gonzalez-Rivas D, Ng CSH, Rocco G, et al. Atlas of Uniportal Video Assisted Thoracic Surgery. 1st edition. Springer Nature Singapore Pte Ltd., 2019:3-289. 